\title{
How I wean patients from veno-venous extra-corporeal membrane oxygenation
}

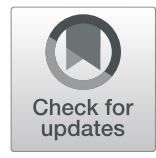

Francesco Vasques ${ }^{1}$, Federica Romitti ${ }^{2}$, Luciano Gattinoni ${ }^{2 \dagger}$ and Luigi Camporota ${ }^{1{ }^{*}+}$

\section{Introduction}

Identifying patients who are ready for weaning and liberation from veno-venous extracorporeal membrane oxygenation (ECMO) is challenging in clinical practice. Compared to the several trials addressing the safety and efficacy of ECMO in severe ARDS [1-4], the body of literature regarding ECMO weaning is remarkably scarce. Therefore, this essential component of the management of patients on ECMO is highly variable and often lacks of a systematic approach [5], analogously to the weaning protocols and spontaneous breathing trials used for liberation from mechanical ventilation [6].

The trajectory from ECMO cannulation to lung recovery and ECMO decannulation consists in the transition from a phase in which ECMO is essential to meet the patient's metabolic needs (i.e. metabolic oxygen consumption and $\mathrm{CO}_{2}$ production) to a phase in which the native lung function has recovered to satisfy completely the metabolic demands, even if with a degree of ventilatory support considered "safe". In between these two phases is a continuum of lung healing, during which lung function becomes sufficient to maintain a gas exchange compatible with life, but at the expenses of a high respiratory drive and large swings in transpulmonary pressures. In these conditions, ECMO has the role of maintaining lung protection partially contributing to the patient's gas exchange [5]. In the effort to track the progress of an individual patient along this imaginary line, it is necessary to measure the relative contribution of the membrane and native lungs in terms of gas exchange, as well as the response of the patient's respiratory drive and mechanics to the variation in ECMO settings.

We propose a physiology-based assessment protocol, which combines an objective assessment of the native

\footnotetext{
* Correspondence: luigi.camporota@gstt.nhs.uk

Luciano Gattinoni and Luigi Camporota are to be considered both as last authors.

'Department of Adult Critical Care, Guy's and St Thomas' NHS Foundation Trust, Health Centre for Human and Applied Physiological Sciences, King's Health Partners, King's College London, 6th Floor East Wing, Westminster Bridge Road, London SE1 7EH, UK

Full list of author information is available at the end of the article
}

and artificial lung function and quantifies the patient's response to a standardised weaning trial.

\section{Patients' selection}

The prerequisites for a weaning assessment is that patients are comfortable, haemodynamically stable and on spontaneous or assisted mechanical ventilation (e.g. CPAP/PS).

In addition, the $\mathrm{PaO}_{2}$ after a $100 \%$ test (i.e. the systemic arterial $\mathrm{PaO}_{2}$ taken after $15 \mathrm{~min}$ of $\mathrm{FiO}_{2}=1.0$ on the mechanical ventilator $)>30 \mathrm{kPa}(225 \mathrm{mmHg})$ and a $\mathrm{P} 0.1<5 \mathrm{cmH}_{2} \mathrm{O}$.

\section{Baseline measurements}

On a daily assessment of ECMO patients, we routinely measure the following:

- Gas exchange variables, including the 100\% test; post-membrane $\mathrm{PO}_{2}, \mathrm{VO}_{2}$ and $\mathrm{VCO}_{2}$ of the membrane lung $\left(\mathrm{VCO}_{2 \mathrm{ML}}\right)$ and $\mathrm{VO}_{2 \mathrm{ML}}$; and $\mathrm{VCO}_{2}$ of the natural lung $\left(\mathrm{VCO}_{2 \mathrm{NL}}\right)$ using volumetric capnometry. This allows calculating the total $\mathrm{VCO}_{2}\left(\mathrm{VCO}_{2-}\right.$ tot $=\mathrm{VCO}_{2 \mathrm{ML}}+\mathrm{VCO}_{2 \mathrm{NL}}$ ) and the proportion of $\mathrm{VCO}_{2 \text { tot }}$ eliminated by the natural lung $\left(\mathrm{VCO}_{2 \mathrm{NL}} /\right.$ $\left.\mathrm{VCO}_{2 \text { tot }}\right)$.

- Ventilatory variables, including the negative inspiratory force (NIF), the P0.1 (as estimate of the inspiratory drive) and the ratio of P0.1/NIF, and swings in oesophageal pressure (if available).

In our protocol (see Additional file 1 and Fig. 1), we assess separately the patient's dependence on ECMO-in terms of both oxygenation and decarboxylation, or decarboxylation alone-by conducting two sequential steps. The first step consists in the progressive reduction of the ECMO $\mathrm{FdO}_{2}$ (fraction of oxygen in the sweep gas flow), while the second entails the stepwise reduction of the SGF. The ECBF remains unchanged throughout the procedure. 


\section{1: Pre-test Criteria}

- Disease Resolution

- Spontaneous Breathing

- Haemodynamically Stable

- OCT > $30 \mathrm{kPa}$
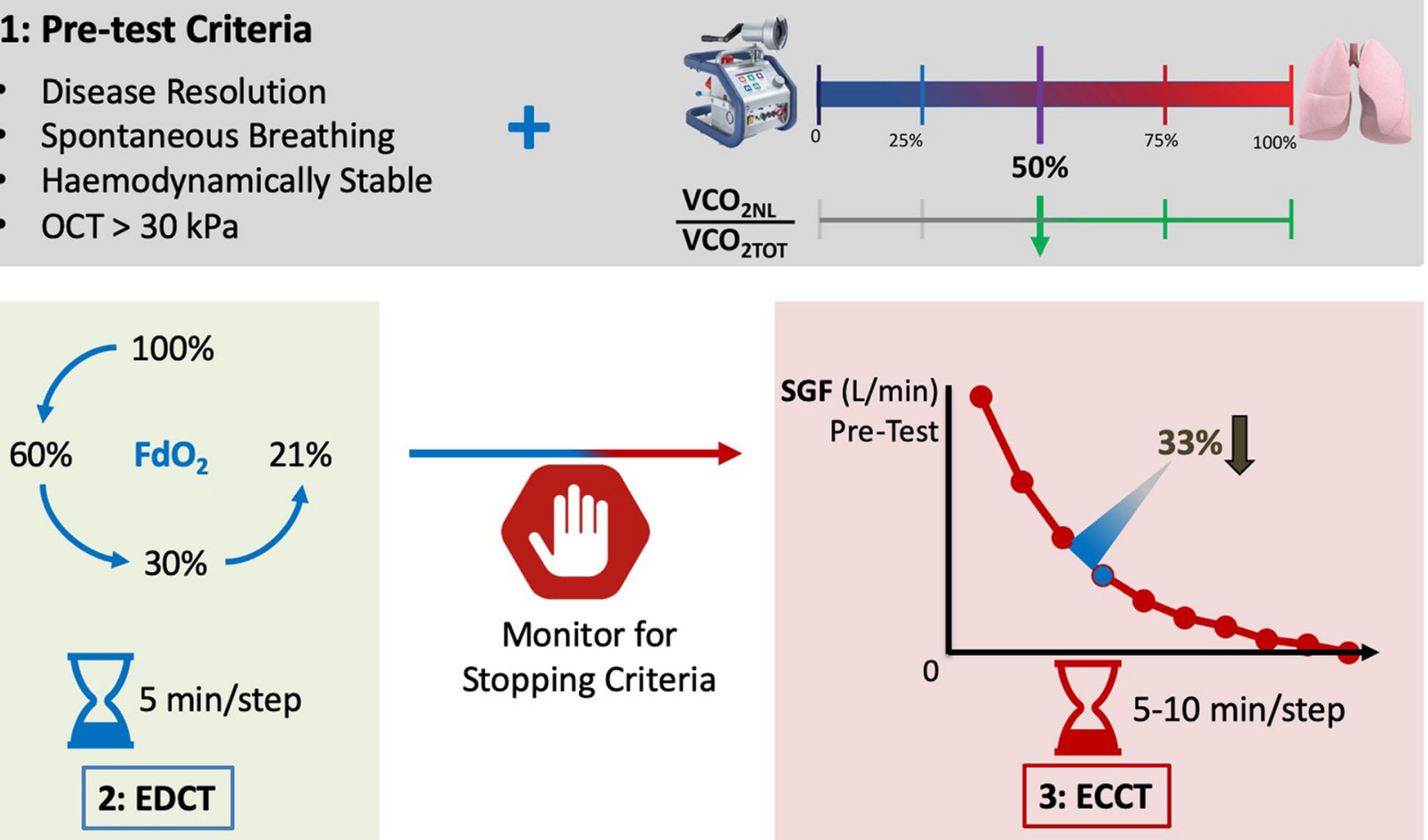

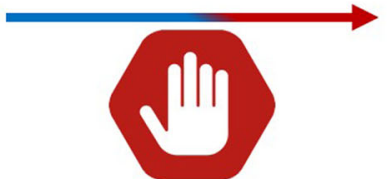

Monitor for Stopping Criteria

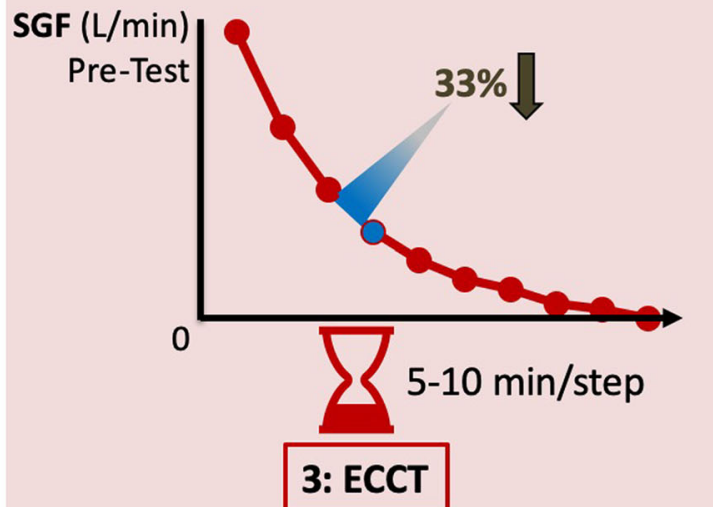

Fig. 1 ECMO weaning test. $\mathrm{FdO} 2$ = fraction on oxygen in the sweep gas; $\mathrm{EDCT}=\mathrm{ECMO}$ de-oxy challenge test; $\mathrm{ECCT}=\mathrm{ECMO} C \mathrm{CO} 2 \mathrm{challenge}$ test; $\mathrm{OCT}=$ oxygen challenge test (FiO2 100\% on the ventilator); VCO2NL = VCO2 natural lung; VCO2ML = VCO2 membrane lung; SGF = sweep gas flow

\section{Step 1: ECMO Deoxy Challenge Test (EDCT)}

Before commencing the assessment, the $\mathrm{FiO}_{2}$ on the ventilator is increased to $60 \%$ in order to prevent the transient hypoxaemia that may happen during ECMO weaning. This frequently observed hypoxaemia is partly explained by the abolition of hypoxic vasoconstriction during ECMO support (due to elevated $\mathrm{SvO}_{2}$ ). The reduction of ECMO $\mathrm{VO}_{2}$ will reduce the $\mathrm{SvO}_{2}$, which will allow the return of the physiologic hypoxic vasoconstriction. This pulmonary vascular response, however, takes time (minutes), and the slow adaptation can lead to a transiently worsened functional shunt (venous admixture). The role of the EDCT is allow time to restore the physiological hypoxic vasoconstriction and optimise ventilation perfusion matching $(\mathrm{V} / \mathrm{Q})$. If $\mathrm{V} / \mathrm{Q}$ is not restored, the functional dead space due to shunt increases and the ability of the natural lung to eliminate $\mathrm{CO}_{2}$ can be impaired.

$\mathrm{FdO}_{2}$ is decreased from 100 to $60 \%, 30 \%$ and $21 \%$ in 5 -min steps. A peripheral oxygen saturation $\left(\mathrm{SpO}_{2}\right)>$ $88 \%$ and $\mathrm{P} 0.1<10 \mathrm{cmH}_{2} \mathrm{O}$ will need to be maintained throughout the test. If a patient meets stopping criteria, the test is suspended and the patient is declared "ECMO-dependent".

If EDCT is successful, $\mathrm{FdO}_{2}$ can be kept at $21 \%$ and the test can proceed to step 2 (Fig. 1).
Step 2: ECMO CO2 Challenge Test (ECCT)

During this phase of the weaning trial, the SGF is reduced by $30 \%$ every $5-10 \mathrm{~min}$, while measuring the patient's response (see Additional file 1 and Fig. 1). Weaning failure and test interruption are indicated by $\mathrm{SpO}_{2}<88 \%, \quad \mathrm{RR}>35 \mathrm{bpm}$ and $\mathrm{P} 0.1>10 \mathrm{cmH}_{2} \mathrm{O}$; $\mathrm{VCO}_{2 \mathrm{NL}} / \mathrm{VE}$ fall by $20 \%$ from baseline; and the negative swings of oesophageal pressure are $<15 \mathrm{cmH}_{2} \mathrm{O}$, or if any signs of distress/instability are evident (Fig. 1).

If the patient's response remains within set limits at 0 SGF, the weaning test is successful, and the clinical team will consider whether to remain off ECMO or reintroduce a variable degree of extracorporeal support pending decannulation.

We believe that a standardised approach to ECMO assessment and weaning is essential to identify patients who are no longer ECMO dependent. In addition, it provides clinicians with a reproducible protocol to ECMO liberation and researchers with a tool to compare duration on ECMO in clinical trials where ECMO duration is an outcome measure.

\section{Additional file}

Additional file 1: Weaning protocol. (DOCX $56 \mathrm{~kb}$ )

Acknowledgements Not applicable. 


\section{Authors' contributions}

LC, FV, FR and LG have developed the present weaning protocol; LC and FV have written the manuscript; FR and LG have reviewed the manuscript; all authors have read and approved the final version of the manuscript.

\section{Funding}

Departmental funding.

\section{Availability of data and materials}

Not applicable.

\section{Ethics approval and consent to participate}

Not applicable.

\section{Consent for publication}

Not applicable.

\section{Competing interests}

The authors declare that they have no competing interests.

\section{Author details}

'Department of Adult Critical Care, Guy's and St Thomas' NHS Foundation Trust, Health Centre for Human and Applied Physiological Sciences, King's Health Partners, King's College London, 6th Floor East Wing, Westminster Bridge Road, London SE1 7EH, UK. ${ }^{2}$ Department of Anaesthesiology, Emergency and Intensive Care Medicine, University of Göttingen, Göttingen, Germany.

Received: 27 July 2019 Accepted: 29 August 2019

Published online: 18 September 2019

\section{References}

1. Abrams D, Ferguson ND, Brochard L, Fan E, Mercat A, Combes A, et al. ECMO for ARDS: from salvage to standard of care? Lancet Respir Med. 2019; 7:108-10.

2. Combes A, Hajage D, Capellier G, Demoule A, Lavoue S, Guervilly C, et al. Extracorporeal membrane oxygenation for severe acute respiratory distress syndrome. N Engl J Med. 2018;378:1965-75.

3. Goligher EC, Tomlinson G, Hajage D, Wijeysundera DN, Fan E, Juni P, et al. Extracorporeal membrane oxygenation for severe acute respiratory distress syndrome and posterior probability of mortality benefit in a post hoc Bayesian analysis of a randomized clinical trial. JAMA. 2018;320:2251-9.

4. Peek GJ, Mugford M, Tiruvoipati R, Wilson A, Allen E, Thalanany MM, et al. Efficacy and economic assessment of conventional ventilatory support versus extracorporeal membrane oxygenation for severe adult respiratory failure (CESAR): a multicentre randomised controlled trial. Lancet. 2009:374: 1351-63.

5. Gattinoni L, Vassalli F, Romitti F, Vasques F, Pasticci I, Duscio E, Quintel M. Extracorporeal gas exchange: when to start and how to end? Crit Care. 2019:23(Suppl 1:203

6. Girard TD, Alhazzani W, Kress JP, Ouellette DR, Schmidt GA, Truwit JD, et al. An official American Thoracic Society/American College of Chest Physicians clinical practice guideline: liberation from mechanical ventilation in critically ill adults. Rehabilitation protocols, ventilator liberation protocols, and cuff leak tests. Am J Respir Crit Care Med. 2017:195:120-33.

\section{Publisher's Note}

Springer Nature remains neutral with regard to jurisdictional claims in published maps and institutional affiliations. 